\title{
Understanding students' use of mathematical processes during a digital escape game
}

\author{
Megan Clune
}

\section{University of Auckland}

Mathematical processes have long been considered an essential component of meaningful learning in mathematics, yet these processes can sometimes be invisible in the mathematics classroom or in learning experiences. This discussion uses the context of a purpose-designed, innovative 'digital escape' game to illustrate how digital experiences might bring mathematical processes to the fore of student learning while offering other affordances only seen in the online space. This article reports on a pilot study conducted with 12-15-year-old school students with the aim of determining if a digital escape game could promote the use of mathematical processes. During the digital escape game, it was found that students engaged with problem-solving, reasoning, communication and made connections within, across and beyond mathematics. The preliminary findings demonstrate how digital experiences may enrich the use and development of core mathematical processes, and it is argued that teachers could use their own expertise and knowledge of their learners to design such experiences, catering to student needs and interests.

Keywords: mathematical processes, escape games, online

The increasing ease of access to digital learning experiences, through devices and the internet, has created enhanced opportunities for learning mathematics, yet there is also concern over whether or not educators are harnessing the full potential of these learning experiences. Additionally, there is little research that seeks to understand how the online space might be used to develop the core drivers of mathematical learning - mathematical processes. In the current climate of curriculum revision, this paper considers the role that digital learning experiences might play in promoting a balance between mathematical processes and mathematical content when designing mathematics learning. In other words: Can digital learning experiences promote the development of mathematical processes?

\section{Mathematical processes}

In essence, mathematical processes are not the 'what' of mathematics but the broad ways of doing, developing, and applying mathematics (Isoda \& Katagiri, 2012). In practice, mathematical processes are inseparable from mathematical content (Neyland, 2004). Many international curricula position mathematical processes, such as problem-solving, logic and reasoning, connections, and communication as core components of learning in mathematics and explicitly refer to mathematical processes in their documents. In Australia, mathematical processes are referred to as proficiencies that strengthen the importance of working mathematically as well as illustrating how content is developed and/or explored. The US Common Core identifies mathematical processes as ways in which we gain and apply content knowledge while the Singaporean curriculum has a similar definition and positions mathematical processes as one of five core elements in a 
problem-solving focussed curriculum. Two core aims of the UK mathematics curriculum are mathematical processes: reasoning mathematically and problem-solving.

The current New Zealand Curriculum (NZC), however, does not explicitly position mathematical processes as a separate component of the curriculum. Instead, mathematical processes are carefully and purposefully woven throughout the mathematics and statistics curriculum statement and achievement objectives (McChesney, 2017). An analysis of the processes implied by the NZC and the processes used in overseas curricula yielded four overarching categories which contain a number of 'ways of doing' or mathematical activities. This analysis is summarised in Table 1.

Table 1

Mathematical processes overview

\begin{tabular}{ll}
\hline Process & Mathematical activity \\
\hline Problem-Solving & $\begin{array}{l}\text { problem posing; experimenting; modelling; using heuristics; } \\
\text { predicting; and investigating }\end{array}$ \\
\hline Logic and Reasoning & $\begin{array}{l}\text { logical, critical and analytical thinking; conjecturing; explaining; } \\
\text { justifying; arguing; proving; refuting; and generalising }\end{array}$ \\
\hline Connecting & $\begin{array}{l}\text { within mathematics; across other learning areas; and into own } \\
\text { lived worlds; to the ideas of others }\end{array}$ \\
\hline Communicating & verbal, written and gestural; defining; and representing \\
\hline
\end{tabular}

These process categories and the mathematical activities they contain were used as an analytical tool to explore what students did when they played a digital escape game.

\section{Escape games and mathematical processes}

An escape room is a game whereby players are physically locked in a themed room and must find and solve a range of riddles, puzzles, locks and mechanisms in order to break out of the room within a given timeframe. Such rooms have been around a little more than a decade and have been explored in the classroom context for approximately the last six years. However, research on their use in education is emergent, with the first studies appearing around 2017. A variation of the escape room is the escape (or 'breakout') game which takes the escape room idea but removes the physical 'room' element. In an escape game, students solve a range of riddles, puzzles and locks in order to open a locked box. A further extension on the escape game is the 'digital escape' (or 'digital breakout'), which is an entirely online experience.

As an educational tool, studies of both the escape room and escape game format have found similar affordances: increased collaboration, motivation, general problemsolving and critical thinking (e.g., Jambhekar et al., 2020). Some studies claim that content knowledge can be improved through the escape platform (e.g., Hermanns et al., 2017). Overall, research to date has been undertaken with learners over the age of 15. Existing studies do not appear to have explored how an escape platform may impact on younger 
learners, nor do any studies seem to have explored the possibility that escape games may be able to promote the use and development of mathematical processes.

In order to explore whether digital escape games might be able to promote mathematical processes, I designed a game that used both the features of an escape game and digital presentation to develop mathematical processes in younger learners. In this paper I discuss emergent observations from examining the discourse and activity of learners as they played the digital escape game in order to explore the potential of this learning experience for using and developing mathematical processes.

I created a digital escape game with features designed to provoke students to use mathematical processes as they worked through the game with a partner. The escape game comprised ten puzzles that needed to be solved in order to open ten virtual locks. The ten puzzles addressed a range of mathematical topics as well as broader knowledge around mathematical history. 'Escaping' required opening all ten virtual locks.

The digital escape game was hosted on a website, with the home page being the 'room' from which the participants needed to escape. The room was titled Ye Olde Mathematics Classroom with objects and images within the room reflecting a 'days of old' theme (see Figure 1).
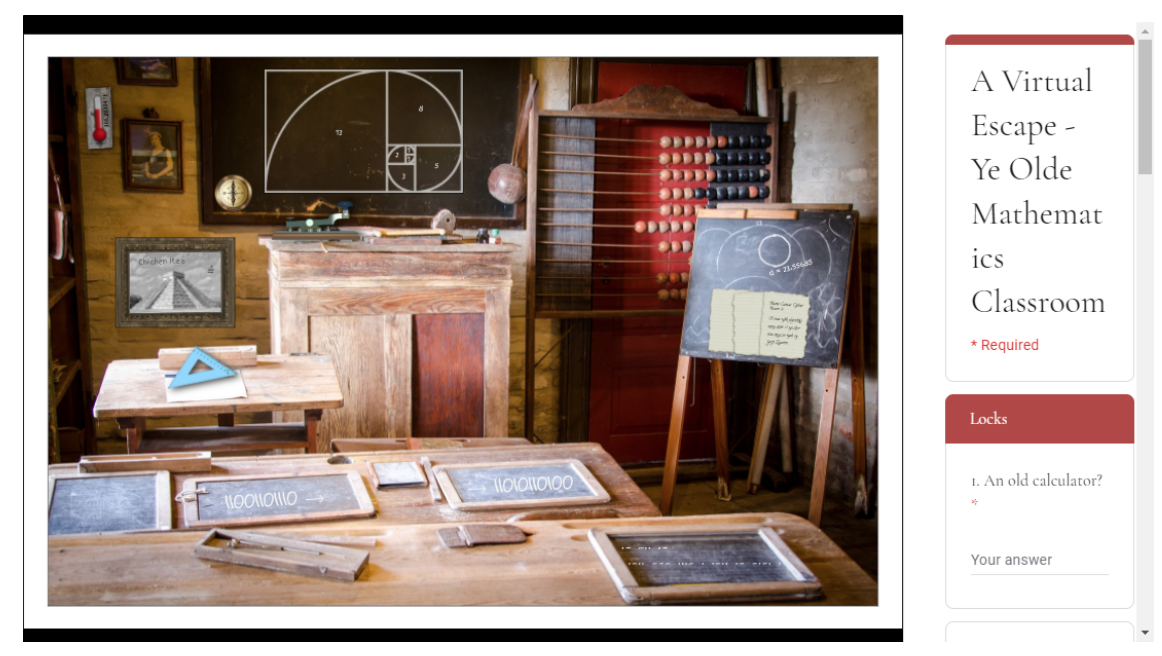

Figure 1. Ye Olde Mathematics Classroom Digital Escape

The majority of objects and images within the room were clickable and linked to other pages within the site with further information and/or problems. The lock descriptors were intended to be somewhat cryptic in their link to aspects within the room. For example, the room contained an abacus. Clicking on the abacus led to another page that showed information about the abacus and another tool. While not explicit, the players needed to find out the name of the other tool based on the information, which would open the lock titled 'An old calculator?'

The digital escape game included elements that were designed to promote problem solving, logic and reasoning, connecting and communicating (see Table 1), through both the content selected (problem types) and the way that the problems were presented in the game (game structure). To explore whether or not these features actually resulted in engagement with the game in a way that provoked use of these processes, I invited three students, one from each 7, 8 and 9 year levels, to play the game online, and they each invited a partner to play with them. The students were remote from each other, and from me, each in our own homes. I hosted a Zoom meeting with both the students as they 
played, and their activity and progress through the digital escape game was captured by audio-video and screen recordings. I also collected any (pen on paper) writing they did during the game. Caregiver consent and participant assent was obtained in writing for these research activities.

Analysis of this pilot study explored the types of mathematical processes that emerged in game play. In the discussion below I consider how the escape game and its digital nature might contribute to developing problem solving, logic and reasoning, connecting and communicating.

\section{What mathematical processes happen when students play the game?}

In this section, I use the mathematical processes and mathematical activities outlined in Table 1 to analyse how three pairs of learners played the digital escape game.

The very nature of the mathematically themed digital escape game means that it would be impossible to 'escape' from the game without engaging in the process of problem-solving. Understandably, problem-solving was the mathematical process that participants demonstrated the most throughout their time in the digital escape game. Although limited use of complex heuristics were observed, 'working backwards' and 'guessing and checking' were evident. Rather than check solutions against the actual problem, participants often experimented with their solutions by testing them out in the locks to see if they worked. Participants generally used online calculators for arithmetic, but there were some instances of calculating on paper using algorithms, especially with the younger participants. The digital escape game appeared to provide an engaging context for the presentation of problems to students. Problems could easily be varied in order to meet students' needs for particular content or problem types. Isoda and Katagiri (2012) state that the aim of a problem-solving approach is for students to engage in learning mathematics by themselves and for themselves. This aim was evident in parts of the game where students often came across problems that they could not immediately solve as they did not have the requisite knowledge. The game itself provided ' $h$ ints' that assisted participants in learning the content required to enable them to open a lock. An example of this was the need to use Pythagoras' theorem to find the height of a rightangled triangle. For two pairs of students, it was clear that this was new learning based on their dialogue.

Applying logic was evident throughout the participants' engagement in the digital escape game, although not to the same extent as problem-solving. In many cases, participants applied logic to confirm their understanding. Participants often had to justify, or explain, their thinking with each other to clarify understanding and ideas. Participants tended to propose conjectures/suggestions as thought processes, while challenges to thoughts and ideas were mostly conversational and reactive to the other's comments. More often conjectures were not challenged but left in limbo especially with the younger participants. Participants did, however, often challenge their own conjectures and thus demonstrated emergent critical thinking. An example of this self-challenge and reactive thought was when one pair, who were trying to find the base 10 value of the Mayan numerals found within the digital escape game (see figure 2), stated the following:

Participant 1: Would it be like six hundred and eleven? Because there are two numbers, but why would you just shove two numbers together like that? 
DOI: https://doi.org/10.26686/nzaroe.v26.6927

Participant 2: Yeah, yeah.

Participant 1: So that's why I was saying six hundred and eleven 'cos that's the Mayan number for six and eleven ... but that's a bit weird.

Participant 2: How did the Mayans write 100?

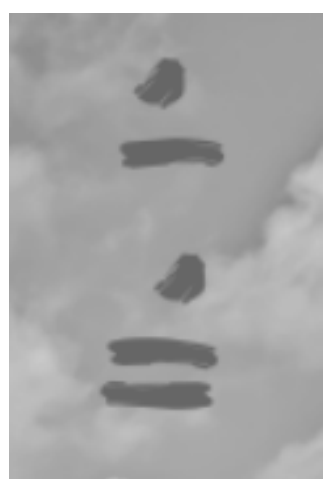

Figure 2. Mayan Numerals

As well as providing information about what the students did with respect to mathematical processes, close observation and analysis of these three pairs revealed things that they did not do. These game players did not use modelling in their approaches to the game's problems. This is most likely due to the way the problems were presented and the problems themselves which did not require them to be modelled. Participants also did not create their own representations of problems, or aspects of mathematics, instead searching the internet for existing representations to aid or support their thinking. Such a reliance on existing representations may likely be a result of working primarily on a screen. Participants were in online mode, so may have preferred to use the 'google it' approach instead of attempting to make their own representations. This approach appeared to be a commonality across participants who often made the suggestion to their peers to 'Google it' instead of explaining a concept.

Engagement with this particular digital escape game highlighted the interconnectedness of mathematical processes. For example, communicating effectively relied on shared definitions and/or representations, which were often instrumental in making connections. The aspect of connecting with the ideas of others was common during the digital escape game; often one participant would say something that would spark a thought for the other participant. However, connecting to the ideas of others appeared contingent on the participants' frequency of communication with each other. The digital escape game itself forced connections to be made between the puzzles and problems in the room and the locks to be opened. Connections within mathematics were also common, while the most common connections to other learning areas were between mathematics and language, and mathematics and geography. Participants also looked for connections between the problems presented and what they know in the real world. Conversely, they applied what they knew of the real world to the problems. For example, proposing that a decoded number may be a date (year) because of the number itself (1646). At the end of the activity, one student commented that they enjoyed the learning that came with the mathematics and gave the example of needing to use Pythagoras' theorem to find a statue that existed in the real world - and now knowing where that 
statue was and what it was called. At times, however, communication became stagnant and researcher intervention was needed to restart dialogue between participants or bring about a refocus in interactions.

\section{Conclusion}

With careful digital escape game creation, mathematical processes, such as problemsolving, applying logic and reasoning, and making connections within, outside and beyond mathematics, seem to be relatively straightforward to elicit. A digital escape game, conducted entirely online and in remote circumstances, appears to provide a platform that promotes verbal communication. In particular, the digital escape game provides an experience where participants are required to convince themselves and others of the legitimacy of their ideas. Effective communication within the digital escape game, however, is dependent on the relationship between the students and may require assistance from a third party, while the remote format of game play may limit gestural and written communication.

It has been suggested that the mathematical processes have become background information for teachers (McChesney, 2017). This implies that because mathematical processes are reflected in the key competencies and embedded in mathematical and statistical content, they are not specifically addressed in lesson design, or noticed and assessed when we think about student progress. Carefully designed digital escape games may have potential for foregrounding processes because the way that they present ideas and provoke engagement demands the use of problem solving, logic, communication and connection.

\section{References}

Hermanns, M., Deal, B., Campbell, A. M., Hillhouse, S., Opella, J. B., Faigle, C., \& Campbell IV, R. H. (2017). Using an "escape room" toolbox approach to enhance pharmacology education. Journal of Nursing Education and Practice, 8(4), 89-95. https://doi.org/10.5430/jnep.v8n4p89

Isoda, M., \& Katagiri, S. (2012). Mathematical thinking: How to develop it in the classroom. World Scientific.

Jambhekar, K., Pahls, R. P., \& Deloney, L. A. (2020). Benefits of an escape room as a novel educational activity for radiology residents. Academic Radiology, 27(2), 276-283. https://doi.org/10.1016/i.acra.2019.04.021

McChesney, J. (2017). Searching the New Zealand curriculum landscape for clarity and coherence: Some tensions in mathematics and statistics. Curriculum Matters, 13, 114130.

Neyland, J. (2004). An ethical critique of the paradigm case: The mathematics curriculum. In A-M. O'Neill, J. Clark, \& R. Openshaw (Eds.), Policy and content in the New Zealand curriculum framework, Vol 1 (pp. 143-160). Dunmore Press. 
Megan Clune is a Professional Teaching Fellow at the Faculty of Education, working in the areas of mathematics, science and technology. As a primary school teacher for 10 years and an Assistant Principal, Megan has always had a passion for digital technologies and the learning of mathematics. She is currently undertaking her PhD exploring how digital escape games might enrich the development of core mathematical processes.

Email: $\underline{\text { m.clune@auckland.ac.nz }}$

ORCiD: https://orcid.org/0000-0002-5630-9248 